\title{
School-Based Policies in Iran
}

\author{
Shamsi Nami ${ }^{1}$ \\ ${ }^{1}$ Faculty Board member of the Organization for Educational Research and planning (OERP), Iran \\ Correspondence: Shamsi Nami, Faculty Board member of the Organization for Educational Research and \\ planning (OERP), Iran. E-Mail: shamsinami@gmail.com
}

Received: February 22, 2016

Accepted: March 18, 2016

Online Published: July 20, 2016

doi:10.5539/mas.v10n12p90

URL: http://dx.doi.org/10.5539/mas.v10n12p90

\begin{abstract}
This paper aimed at examining school-based policies in Iran. School-based approach has been dominated educational systems of developed countries over the past four decades. Delegation of authority to lower levels, particularly to schools for decision making, implementation, monitoring, and evaluation is central to this approach. Efforts have been made to formulate, plan, and implement school-based policies and programs in Iran over a decade. This paper attempts to delve into the quality and quantity of these efforts by verifying and analyzing assertions and implications of Iran's 3rd, 4th, and 5th Development Plans, Theoretical foundations of fundamental Transition in Formal public Education in Islamic Republic of Iran (2011) and laws and regulations approved by Iran's Supreme Council of Education. The results indicated that although the above - mentioned documents and plans focused on the need for reforming structures and organizations, using non-governmental power and private capital, reducing government's tenure, encouraging stakeholders' participation, and favoring school independence, the quality and quantity powers assigned were incompatible with school- based assumptions. Delegation of authority was mainly centered around the decision making on how focused plans should be implemented. While many cooperative organizations have been established in schools through these policies and laws, these efforts are not based upon a comprehensive evaluation on which they can be judged. However, limited amount of evaluation has been carried out, but according to the experts' experiences and ideas, the intended goals has not been fully achieved.
\end{abstract}

Keywords: school-based policies, Education, national document, supreme councils' approvals, development plans, Iran

\section{Introduction}

One of the policies that have been raised about 1970s, is prevailing school-based approach in educational system. Its main idea is providing ability to their decision-making levels that are directly involved in activities. School-based approach is a trend due to pluralism, accountability, reception of educational standards, national monitoring and creating competition can help increase the efficiency of the educational system (Morphy \& Beck, 1995).

What that paved the way of this trend's dominance is the complex nature of education. Being far from school situation, considering all affecting elements, detecting their rate of effectiveness, giving correct measures to the main and secondary factors and paying attention to subsidiary and secondary elements and recognizing the student's interests all and all make this process more complicated.

The scope and depth of the problem becomes more severe along with the lack of regular assessments of the situation and gathering valid research findings and decisions which are being taken are seriously at risk of errors and mistakes. (Nami, 1998; Matin, 2000).

According to this, the school-based movement and delegating the authority of decision-making to lower levels of the educational system has matured in recent years in the world's leading countries, including Canada, England, New Zealand, Australia, Netherlands, Belgium, Spain, and USA (Murphy and Beck, 1995).

Although in different concepts of relevant literature we encounter various terms including "school-site management", "school-centralized management," "decentralized-school management", "school-based decision-making", "school-site autonomy", and "school-based management "(Murphy and Beck, 1995), they are generally at the center of strategies related to involvement, decentralization, and the delegation of authority. 
According to these strategies, the operational and lower levels of pyramid are responsible for the related decisionsBy participating stakeholders in decision makings and flow of ideas, operational levels try to intensify their sense of commitment through increasing the sense of ownership, so that they can link their sense of identity and existence with the achievement of organizational goals (Cheng,1996).

As a result of global movement and increased social demands placed on education system, some movements have been started in our country in this field in the late 1991s. So, the school-based policies, as one of the fundamental ones, were introduced by the Minister of Education in 1997 to improve the quality of education by increasing the roles of schools and lower levels in educational decision makings. Then, the reflection of schoolbased approach in the country's Development Plans (as a strategy to reduce the centralization and government involvement) and in high level documents, the approval of the related laws and regulations in Supreme Council, the actions and measures taken by some educational planners and implementers are among the factors that contribute to prepare the way for a school- based approach. reviewing and investigating these issues are at the heart of this paper.

\section{Methodology}

This study is based on a qualitative approach. To collect data, assertions and implications of Iran's 3rd, 4th, and 5th Development Plans, Iran's Fundamental Transition Document of Education and its theoretical foundation, laws and regulations approved by Iran's Supreme Council of Education during this study, and content of document and related research reports and studies were reviewed and analyzed.

\subsection{Findings}

The first part of this study focused on investigating the direction of Iran's Development Plans, including 3rd Plan(2000-2004), 4th Plan(2004- 2009), and 5th Plan (2009- 2014), and Theoretical foundations of fundamental Transition in Formal public Education in Islamic Republic of Iran (2011) in terms of decentralized education.

The results from the research showed that the main orientation of the 3rd Development Plan was reforming the structure, administrative organizations, and management of the country and assigning the delegation of authority to the lower levels in order to reduce the government role in Education. Based on the general approach of this plan as mentioned, the country's education system, as one of the significant administrative organizations, should also be taken into account in this plan. It should go through the reform movement of administrative structure and management and re- engineering of systems, methods, and operating procedures with the focus on decentralized principle Iran's 3rd Development Plan (2000-2004).

Evaluation carried out by the country's Management and Planning Organization indicated that the direction of the 3rd Development Plan in Public Education concentrated on quality development of activities and quality improvement of educational endeavors. Paying attention to increased public participation and the role of private sector in achieving educational goals, optimal use of available capacities, facilities, and resources, and the reform of institutional and organizational structures are amongst factors which have been highlighted in the 3rd Development Plan, Economic Report 2002 and monitoring the performance of the first three years of Iran's 3rd Development Plan(2003), In the Iran's 4th Development Plan (2004- 2009) access to equal educational opportunities, expansion of knowledge and skills, productivity improvement in human capitals, and quality and quantity development of public education were introduced as the main policies. Determining policies and designing different programs, the government was obliged to guarantee the realization of the Plan. What is particularly concerned with school-based approach is the obligation of the government to take the necessary measures for the independence of schools. Accordingly, in addition to providing general credits for education, the government should take the required measures to develop financial, managerial, administrative independence of educational units(schools) so that it can make the best use of capitals and implementation power of non-governmental sectors to develop schools' capacities and increase their productivity(Islamic Republic of Iran's 4rd Development Plan).

The main direction in the Iran's 5th Development Plan (2010-2014) is fundamental change in educational system within the framework of the law. Several priorities were considered to make such changes, including changes in educational programs, curriculum development, educational guidance, evaluation system of academic achievement, professional competencies of human resources, information and communication technology (ICT), physical health, and physical education. Although accomplishing all these mentioned priorities depends on school- based policies and the strength of school position at the levels of management pyramid, there are obviously no specific cases of these priorities that can be attributable to school-based policies (Islamic Republic of Iran's 5rd Development Plan). 
In the Document of Fundamental Transition in Education, it is necessary to make changes in all dimensions of existing educational system. The theoretical findings of development have implied that fundamental transition means regular and harmonious changes that involve all elements, components, and relationships within and outside the system and the elements and factors contributing to effective performance. This regular change cycles are known as "shift/rotation from status quo to the desired status". Among ten mentioned shifts, at least four shifts- from educational-institutional to socio-cultural and productive human capital, from external control and placing limitation to self-monitoring (virtue, value- rational orientation, and responsibility), from monopoly in education to participation and accountability of contributing factors and elements, from compatibility with the environment to identity- seeking and resistance to the adverse conditions and their changing- are regarded as school- based components.

In six sub- systems of formal and public education, the operational courses of these shifts have been shown. In sub-system of educational governance and management, the shift occurs from administrative and control management to educational governance based on system of Islamic criteria and from centralization changes to participation and responsibility based on collective wisdom. In sub-system of curriculum, the shift can be shown from entirely centralized curriculum development to curriculum development based on participation of all effective and contributing factors and elements at all levels. In the sub-system of teacher training and human resources, the shift can be seen from the teacher as a sole curricula decision implementer to the teacher as a decision maker in the curriculum development process and from closed organizational culture( restricted teachers in school environment) to scientific participation and transfer of experiences at different (school, local, national, and international) levels.

In sub-system of allocation of financial resources, the shift occurs from monopoly in the provision of resources to participation in financing and from resource costs to management and optimal resource policy and intended uses of resources. In the sub-system of space, equipments, and technology, the shift is from providing classrooms to organizing learning opportunities and from schools without identity, equipments, and technology to schools with good identity and educational center in local areas.

Besides, in sub-system of research and evaluation, the shift is reflected from allocation of research opportunities to formal centers and professional researchers at macro levels to providing research opportunities and spreading the research at all levels and from theoretical and academic approach to educational research and research for the sake of research to the practice-oriented diagnostic and practical research on which decision making and application can be based( Theoretical Foundation of Islamic Republic of Iran's Fundamental Transition in Educational System).

As a result of these shifts, school from 1404 perspective (based on Iranian calendar) is viewed as the nation and government's reliance on the country's development and a local educational center, that has the right to make decision and plan in operational areas within the framework of local, regional, and national policies, that play a role in informed, rational, responsible choices students can make in the process of their personal, family, and social life, that has the capacity of accepting individual differences, of exploring and directing diverse natural talents, of responding to students' needs, interests, and dispositions in accordance with interests and framework of the system based on Islamic criteria, that has the ability to make decision about public formal education system, and that links effectively to issues and problems of the society at local, regional, national levels, along with active participation in social life(Fundamental Transition Document of Education).

The second part of this study aimed at examining the laws and regulations approved by Supreme Council of Education and School-Specific Commission since the beginning of the implementation of the 3rd Development Plan. To collect data, all decisions made by Supreme Council of Education reviewed during this period. Among all approvals and decisions made by Supreme Council of Education and School-Specific Commission, the followings are invoked in this paper:

1- Implementing school regulations, approved 10/8/2000

2- Formation of student assembly regulations, approved 14/3/2002

3 - Casting votes to carry out experimental designs of educational complexes in academic year 2002-2003 in some country's school districts, approved 2002/3/14

4- Guideline for establishing educational complexes, approved 2002/4/23

5- Regulations of the board of trustees of school donors, approved 2005/4/28

6- Regulations of expanding public participation in school, approved 2004/ 6/8 
7- Internal regulations of schools' board of trustees including regulations of expanding public participation, approved 2004/7/14

8- Continuing and expanding activities of schools ran by the board of trustees, 2008/2/12

9- Regulations of developing public participation based on the management of schools' board of trustees, approved 2009/4/21

10- Regulations of educational complexes for rural and tribal groups, approved 2010/12/14

11- Educational complexes regulations, approved 2011/7/6 (Decisions by Supreme Council of Education ,2011).

\subsection{Analysis and Interpretation of Information}

Analysis and interpretation of this information requires attention to school-based philosophy. The school is a collection of necessary factors and conditions that the purpose of bringing them together side by side would be providing a platform for education of school-age people with the right quality and quantity. Now, how these people should be attracted to school, how they should become eager to learn, what and how they should be taught, how to find out what they have learned and what not, how to guide them to realize what not being learned, and what are about to learn and hundreds of other why and how need to be examined correctly, quickly and accurately to achieve acceptable results and a school can be treated to be successful in accordance with the criteria and standards. How to investigate hundreds of why and how aforementioned and decision-making on them are the matters that determine the task of the educational system of whether centralized or not. In other words, when in a educational system, policy makers, principals, and high-level experts make decisions on higher education goals, content of textbooks, learning materials and even supplementary forms and characteristics, evaluation methods of academic achievement, how to attract, select, train in pre-service and in-service, evaluation of the performance, characteristics of the space, equipment, and technology, financial resources and ways to expenditure and even regulations such as how to register, how to cover, and discipline etc., in a case, this is a centralized system and when in each of the above areas, middle and operational principals and stakeholders and beneficiary individuals, such as teachers, students, parents, trustees, and experts and professionals are delegated some authorities to decide for themselves, in this case, based on proportion of the authorities delegated, the educational system is to achieve decentralization. Delegation of authority to schools is done in the context known as a school-based approach which is governed nearly four decades on the educational systems of developed countries. Now, the measures should be interpreted by this view, in the context of school-based education in our country.

Study on the orientation of Development Plan and Fundamental Transition Document shows that in these documents, though the school-based approach is not clearly mentioned, the spirit dominated and the terms stipulated in this documents emphasized to reform the structure of the organizations, re-engineering of systems, procedures and methods, and function adjustments, government involvement, using the participation of public and of private-sector executive capital and power, improving the productivity of human capital, financial, managerial and administrative independences of the schools, fundamental change in all sectors of the education system, including curriculums, evaluation, professional standards of human resources, ICT and physical education and acknowledging 10 revolutionary rotations or shifts to be necessary of all elements, components and processes and relationships inside and outside the educational system from the status quo to the desired situation.

The decisions of the Supreme Council of Education and the Specific Commission in this regard are homophones with the above mentioned programs. The content of the regulations and directives adopted show that the participation of a wide range of students and their parents, principals, teachers, experts, donors and trustees in form of the organizations such as the Council of teachers, school council, student council, student council, PTA, and the board of trustees would be considered, which shows that, in formulating these laws and regulations, the need for the participation of these people has been considered. But looking at the duties expected to them shows that in this case, rather than paying attention to the content of the containers, the form and shape of the containers are paid more attention. It seems that this even if full implementation of the partnership can only make waves on the water surface. In other words, when in staff field, in our educational system, on the one side, with no rival, the curriculum goals, content development and production of hundreds topics of textbooks and educational materials and their distribution with a circulation of millions are set and even evaluated, on the other side, the policies and programs for attracting, selecting, pre-service and in-service training of teaching staff, financing, provision of space and equipment etc. are designed, implemented and evaluated, not only the policies, procedures and laws but also regulations in areas such as registration, student discipline, clothing and so on are developed and communicated, these organs, councils and boards of trustees ago provided in regulations and 
guidelines, if established in the best case, what could they provide a significant contribution.

Of course, this does not mean that the powers delegated to the Council and the Boards are ignored, but it should be noted that there is a difference between the delegation of authority to do good things and that to do thing well. It seems that in the regulations and guidelines what is considered is that these councils and boards will help to carry out the work determined well, not that they be empowered to make and take and then implement and evaluate the decisions fundamentally about good things to the schools. Although on the introduction of the regulations and guidelines it is discussed the delegation of authority and implementing school-based policies and participations of relevant and influential in key areas such as programming, implementation and evaluation, but the evaluation of duties assigned to the organs, councils and boards would indicate that the authorities of these people revolve around the pivot of the development of annual plan in framework of criteria determined, care, and supervision on the activities of the school, the provision and implementation of extra-curricular plans and the same things that however, due to the above-mentioned materials of the educational centralized planning system in the country's educational system, practically, it is not possible other than limiting the authority delegated to decide on extra- and beside-activities and programs and measures implemented. It seems that the most important motivation for the discussion of school-based and delegation of authority to lower levels of the educational pyramid is seeking private funding and implementation of effective strategies to attracting the financial participation. Obviously, without providing the context and cognitive structures to reduce the concentration on all aspects and dimensions of the educational system, it cannot be benefited from the blessings of participation. If the authorities in various fields would be concentrated in one place and due to the inability to perform the necessary funding, the people are asked to help financially and the delegation is meant purely financial participation, it would be natural they don't shake this hand. It should be recognized that the education systems are centralized would not tolerate decentralized movement. It cannot take a step in a sector of the educational system without considering the overall structure of the system towards decentralization. So it is necessary that the required modifications be imposed to provide the ground to delegate authority; and all sectors of this field proceed coordinately that centralization of one sector does not block another sector's move towards the decentralization and not indispose participating programs to be passive, stereotype and superficial (Ghasemi Pouya, 2006- Sanjari, 2001 and Niknami, 2002).

However, it seems that when the education system is moving towards decentralization and delegation of authority to the lower levels, it is not consider a road map, and without a comprehensive and timed plan, a loophole would be made in this way, however, walking this way leads to the establishment of capacities including school council, teachers' council, school council, parents and teachers associations, student meeting, boards of trustees and educational- training complexes. It is worthwhile to note that even though the containers are not filled with the strong content, the formation of these have been seized and the agents and students must take advantage of them that through the relevant benefits, the possibility of enriching the content and fixing the deficiencies of these containers were created, but has it been achieved?

In this case, it should be said that contrary to the requirements of designing and implementing a new program, except in one case, mainly the implementation of these programs or evaluation has been not done or done on a limited basis. Evaluating the measures taken in the evaluation of the results of implementation of the decisions of the Supreme Council in this regard show that the only guideline to form educational-training complex have been evaluated twice in two stages and in timed way by the Institute of Education Studies (Saki, 2004 and Navidi, 2005), and regulation of public participation has been evaluated once by Research Institute mentioned (Chaichi, 2007). As a part of implementing regulations under the disciplinary regulations based on the order of the Supreme Council (Ahmadi, 2005) and another part of it in the form of a thesis (Ghasemi, 2004) have been evaluated. However, the cognitive, formative and final evaluation would be requirements of a program, based on their results, to provide the necessary facilities and conditions prior to the implementation of the plan and to take care of the plan process and ultimately identify possible deviations from target and modify the route and judge the results and outputs of the program.

According to the results of evaluations carried out, of the barriers of the educational system organization in school-based field it could be aborting the plan in the planning stage and even in design stage. In the designed and implemented programs in the field of authority delegation to lower levels and participation attraction, it is seen that these programs are not based on research infrastructure and appropriate mechanisms would be expected for support, supervision and evaluation of the program and after hasty designing, they have been notified to the execution units, without adequate oversight on the executive steps and even enjoying cognitive, formative and final evaluating. So, if the problem has occurred in any phase of the program, the executive with no advisory and oversight aid suffered the consequences of the problems in the implementation duration and thus against the 
deviation and passivity of the program were diagnosed to be indifference (Saki, 2004 and Navidi, 2005).

It can be said that another major factor has caused limited capacity in the field of school-based created not to be utilized adequately by the students and practitioners of operational levels would be the problems related to lack of cognitive maturity to the human in the field of their own participation and human rights and citizen.

The existing barriers in cognitive area of the education system authorities would play an important role in the ineffectiveness and inefficiency of programs which are supervisor to attract the participation of people. Some of the barriers return back to the principals as designers and clients of the programs and another, to staff as a host. When the principals do not have sufficient knowledge in the field of institutional partnerships and they are not aware of the concept and necessity of partnership and its positive consequences and ways of participation attraction and consequently do not have the insight and skills enough and don't feel motivation to engage the employees' participation, and inversely, they consider the employees who are attracted to participate as a threat to loss the power of their own post and the ability to control and on one hand, they cannot believe subordinates, and on the other hand, do not have enough confidence to entrust the affairs to them (Pardakhtchi, 2002). Although the sufficient structural capacities would be created to attract the participation, the principals cannot and do not want to attract the participation from lower levels.

About the staff, the cognitive context plays role. Lack of knowledge, attitudes, skills and motivation of the employees block the path of any successful program of participation. Lack of awareness, the unhappy job situation, lack of motivation and inability to participate lead them to treat the cooperative programs to be as burden in order to increase the volume and pressure of work and

\section{Summary and Conclusion}

After nearly four decade that school-based approach has dominated world educational systems, it has become the focus of attention of Iran's educational system from the past decade due to the emphasis of new theories of educational leadership and management on economic, political, social, cultural, legal, managerial, and human's effects of student, parent, educational authorities, and society's participation in children's education. The most important reason for this negligence was unbearable problems which the centralized education structure had been facing, such as providing increasing costs of education, increasing unacceptable educational dropout rate and its consequences, facing a drop in the quality of education, and being ineffective of changes made through centralized programs.

Accordingly, since Iran's 3rd Development Plan has been implemented, focusing on school-based policies and preparing the ground for its implementation become one of the missions of the Ministry of Education. Despite this, although policy makers and top-level and middle-level managers have discussed and emphasized the importance of school- based policies in the meetings and lectures, they haven't formed a logical framework and designed a timely comprehensive systematic plan in practice. However, it should be noted that some regulations were introduced in this field which showed ineffectiveness in practice due the lack of structural and cognitive requirements.

Generally speaking, despite the inclusion of school-based approach in country's macro policies and plans, the measures taken in this regard has been inadequate in that there were no required changes in structure and organization of this centralized education and the ground to assign the delegation of authority to the lower level of the system and giving priority to school were not prepared on one, leaving the space for miscellaneous programs being improperly implemented without any comprehensive framework and research basis while no appropriate mechanism was provided to support, monitor, and evaluate them. The program's managers were incapable of directing and motivating staff and providing sufficient financial, material, and information resources to achieve their goals in this case. As a result, staff was passive and acted inappropriately rather than being enthusiastic about implementing this cooperative programs properly, leading to ineffectiveness of the program in practice.

To solve these problems, in addition to providing structural arrangements, assigning authorities, allocating required resources and facilities, selecting managers based on meritocracy, and eliminating barriers to staff's participation, care should be given to empowerment of human resources both to managers and staff because any change or reform in any organization is subject to individuals' knowledge, ability, and motivation.

\section{Research Implications}

Due to the lack of systematic school-based measures, it is suggested that the following research works and implementation measures in the form of a timely comprehensive written plan be useful:

1- Fundamental changes should be made in the structure of educational system in such a way that making 
decisions about important components of education can be assigned to the lower levels of educational pillars including provinces, districts, and schools.

2- The delegation of authority to schools should not be limited only to plans for implementing legislative and regulative acts and seeking non-governmental funds. But, based on the fact that constituent councils at school levels, including boards of trustees, teacher councils, school council, student councils, parent-teacher meetings, and teachers are the closest parts the schools can trust on their ideas and actions.

3- The required training programs should be designed and implemented for different participatory groups in various ways to empower people engaging in education in order to take the shared responsibilities and understand the necessity for acquiring needed knowledge and skills.

\section{References}

Ahmadi, A. A. (2005). Study on students' and school administrative staff's attitudes towards school's disciplinary regulations. Tehran: Supreme Council of Education Research.

Pardakhtchi, M. H. (2002). School-based policy, empowerment, and accountability necessary for any reform of Education (presented in Article Collections of reformed engineering in Education, volume I). Tehran: Center for Education.

Chaichi, P. (2007). Evaluating regulations on expanding public participation in schools. Tehran: Center for Education.

Saki, R. (2004). Evaluating pilot implementation of guidelines for establishing educational complex. Tehran: Center for Education.

Sanjari, R. (2001). Looking at shortcomings of participatory school-based management. Tehran: Center for Education.

Document of Iran's Fundamental Development in Education. (2011). Tehran: Ministry of Education.

Ghasemi, M. (2004). Study on the effectiveness of schools' implementing regulations from secondary school administrators' perspectives of district3 in Tehran related to school-based policy. MA thesis. Tehran: Shahid Beheshti University.

Ghasemi, P. E. (2006). Public participation in Education, Tehran: Center for Education.

Economic Report 2002 and monitoring the performance of the first three years of Iran's 3rd Development Plan. (2003). Volume II, cross-sectorial areas. Tehran: Iran's Management and Planning Organization.

Matin, N. (2000). Investigating the application of research findings in Education, Tehran: Center for Education.

Decisions by Supreme Council of Education. (2011). Tehran: Site of Secretariat of Supreme Council of Education.

Theoretical foundations of fundamental Transition in Formal public Education in Islamic Republic of Iran. (2011). Tehran: Supreme Council of Education.

Nami, S. (1998). Study on barriers to the application of research findings to educational decision making, Tehran: Center for Education.

Navidi, A. (2005). Evaluation of educational complexes, Tehran: Center for Education.

Niknami, M. (2002). Decentralization and cooperative decision making: Effective approach to improving the effectiveness and accountability of school (presented in Article Collections of reformed engineering in Education, volume I), Tehran: Center for Education.

Cheng, Y. C. (1996). School effectiveness and school - based management: A mechanism for development, New York: The flamer press.

Murphy, J., \& Beak, L. G. (1995). School - based management as school reform. California: Corwin.

Iran's 3rd Development Plan. (2000-2004).

Iran's 4th Development Plan. (2004- 2009).

Iran's 5th Development Plan. (2010-2014).

\section{Copyrights}


Copyright for this article is retained by the author(s), with first publication rights granted to the journal.

This is an open-access article distributed under the terms and conditions of the Creative Commons Attribution license (http://creativecommons.org/licenses/by/3.0/). 